\title{
TEACHING AS COACHING: EXPERIENCES WITH A VIDEO-BASED FLIPPED CLASSROOM COMBINED WITH PROJECT-BASED APPROACH IN TECHNOLOGY AND PHYSICS HIGHER EDUCATION
}

\author{
Herena Torío iD \\ Institute of Physics, University of Oldenburg (Germany) \\ berena.torio@uni-oldenburg.de
}

Received September 2018

Accepted April 2019

\section{Abstract}

The role of faculty in higher education as knowledge disseminators within the knowledge and digital society can be completely redefined. This paper presents results from a video-based flipped classroom approach combined with a project-oriented learning arrangement. I show that videos combined with a project-based learning setting can be a powerful tool to facilitate the shift from knowledge dissemination to knowledge appropriation. Besides, results show a high level of student's satisfaction and achievement during the course. The self-perceived competences obtained by the students during the course and those estimated qualitatively by the lecturer on the ground of the formative and summative evaluations reach far beyond those possible in a similar course with a traditional teaching approach.

Keywords - Active learning, Video-based, Flipped-classroom, Project-based, Higher education on energy and technology.

\section{To cite this article:}

Torío, H. (2019). Teaching as coaching: experiences with a video-based flipped classroom combined with project-based approach in technology and physics higher education. Journal of Technology and Science Education, 9(3), 404-419. https://doi.org/10.3926/jotse.554

\section{Introduction}

With an enormous amount of educational material, books and papers available per mouse-click explaining from the more fundamental to highly complex physical principles, the role of lecturers as knowledge disseminators needs to be completely rethought. Information, from any topic and in virtually any level of depth is widely available via digital technologies. In such a context the role of higher education lecturers should not be limited to merely making accessible contents in terms of information and knowledge to the students. An appropriate role understanding of teaching faculty should rather focus on knowledge production, transformation, application and its critical appraisal instead (McDaniel et al., 2000).

Numerous approaches such as situated learning (Wildt, 2005), research-based learning (Wildt, 2011) or more generally stated active learning approaches (Misseyanni, Lytras, Papadopoulou \& Marouli, 2018) support this new role understanding (Blom, 2000). All of them foster and promote strongly the so-called "shift from teaching to learning" (Berkemeyer \& Schneider, 2009: page 123; Schneider, Szcyrba, Welbers \& 
Wildt, 2009: page 5). Teaching activities and faculty roles in such paradigms should create learning environments and settings where learning process can be effectively supported by means of suitable coaching and consulting by the teacher. Such approaches lead to an increased students motivation while giving also orientation and feedback (Wildt, 2011; McDaniel et al., 2000).

However, despite a growing evidence of the benefits of such active learning approaches (Arnold, 2013; Bonvillian \& Singer, 2013; Dadach, 2013; Fry, Ketteridge \& Marshall, 2009; Waltdrop, 2015), there is still a big potential for fostering their implementation in engineering and physics higher education (Torío \& Brudler, 2015; Waltdrop, 2015). Innovative teaching approaches are implemented based on the personal engagement of motivated faculty members (Torío \& Brudler, 2015). The identification of suitable educational tools can greatly encourage faculty members to rearrange their course design and implement such active teaching. In this work the combined use of videos, a flipped-classroom and project-based arrangement for successfully promoting such active learning settings is analyzed.

In this paper a practical experience from the implementation of such a didactic approach, aiming at fostering active learning by bridging the gap between theory and practice and enhanced coaching by the lecturer by means of a flipped-classroom methodology, is presented. Simple "slides-with-voice-over" videos developed with relatively low faculty effort were used as a basis for establishing a flipped-classroom approach. This enabled self-learning of theory to happen outside the classroom and promoted discussion and problem-solving during the presence lecture time. The theory presented in the videos needed to be applied by the students in order to complete a project. This project-work was chosen as examination form and intended to motivate students to achieve a deep understanding of the theory presented in the videos.

The main research questions in this paper address (i) whether simple videos are a suitable educational resource able to engage students in the understanding of complex theoretical concepts, (ii) whether the use of theory videos combined with project-work creates a useful coaching environment promoting a significant learning experience.

After a thorough description of the created learning environment, the research methodology and main results addressing student's satisfaction with the course design as well as their self-perceived achievement within it are presented.

\section{The Course Design}

The postgraduate level course presented here dealt with the physical principles governing the operation of solar thermal systems and their components as well as relevant methods for assessing their performance. The course had a workload of $90 \mathrm{~h}$ for each student, corresponding to 3 ECTS credit points. It is part of the compulsory curriculum of the Master Programme "Postgraduate Programme Renewable Energy (PPRE)" taught at the University of Oldenburg. The course is elective to students from other master programmes. The analysis here corresponds to the following cohorts: 7 students from the PPRE Programm; 5 students from the European Master in Renewable Energy; 1 student from the Master Physics; 8 students from the Engineering Physics Master and 3 students from Sustainability Economics and Management of the University of Oldenburg. In total 24 Students from 17 countries of 4 continents with previous degrees going from mechanical and electrical engineering to physics and economics attended the course. Results presented here correspond to a single course conducted from October 2017 to January 2018.

The theory of the course was structured following a bottom-up approach: first we dealt with the main physical principles underlying the operation of solar thermal system components (e.g. solar collectors, thermal storage, heat exchangers...) in detail. Once all relevant components were introduced, the system perspective followed, introducing the detailed characterization of the system behavior and the links between component and system behavior.

The course followed a project-based learning approach. The goal of the course was to give students a sound and solid understanding on the principles governing solar thermal systems, their main components 
and the main factors influencing system's performance. Based on the theory presented in the videos, students were asked to develop a project analyzing the performance of a solar thermal system in detail using state-of-the-art empirical assessment methods. The group project-work was chosen as an essential part of the course and represented its summative examination form. The project-work aimed at sizing a solar thermal system for a particular application for solar heat production (domestic hot water and /or space heating supply, process heat or solar cooling supply) in a particular location and assessing its annual performance. Paired in groups of two, students had the choice of defining the system application as well as its location. They defined their own particular application (project) and performed all required calculations following either the F-chart or F-chart-utilizability methods (Duffie \& Beckmann, 2013). Finally, student groups presented and reported on their system design, their chosen system size and the resulting system performance for the given application. A sensitivity analysis on the performance of the project as a function of relevant system criteria (e.g. size of the solar collector field, chosen field mass flow, storage size, etc.) was also part of the project work. Through the project calculations and its results students could get a thorough understanding of the interlinks between different system variables and their influence on the whole system performance.

The methods used for system performance assessment (F-chart and F-chart-utilizability methods) are empirical methods allowing to analyze system performance soundly without requiring dynamic system simulations, which would be out of the scope and possible workload of such a course. However, they are complex methods requiring a sound understanding of several variables and a previous accurate calculation of several system parameters. To facilitate the understanding of these processes and steps, I intended to enhance the coaching time during the presence lectures. In order to maximize the student-lecturer interaction and the room for coaching within the lecture time I chose a flipped-classroom approach. Figure 1 shows the time structure of the course for the first two weeks. Every week students received a video-based lecture of 20-40 minutes as theoretical input with the necessary background and explanations for thoroughly understanding the theory related to (i) either a system component or (ii) the system performance and its assessment method. Additionally, weekly assignments related to the theory gave students the chance to apply the theoretical knowledge to concrete steps for developing their project. The students had 7 days to go through the video-lectures and weekly assignments at their own pace. After the self-working time on the weekly videos and assignments, students had the full length of the presence lecture time to clarify doubts and questions on the explained theory.

\begin{tabular}{|c|c|}
\hline Session 0 & Introductory session \\
\hline Week 1 & $\begin{array}{l}\text { Self-study of/with the video } \\
\text { Video on solar thermal collectors: } \\
\text { operation principles, performance indicators, types. }\end{array}$ \\
\hline Session 1 & $\begin{array}{l}\text { Solar thermal collectors: clarifying questions on the } \\
\text { video and working on proposed weekly assignments }\end{array}$ \\
\hline Week 2 & $\begin{array}{l}\text { Self-study of/with the video } \\
\text { Video on solar collector fields: } \\
\text { operation strategies, performance indicators, types. }\end{array}$ \\
\hline Session 2 & $\begin{array}{l}\text { Solar collector fields: clarifying questions on the } \\
\text { video and working on proposed weekly assignments }\end{array}$ \\
\hline $\begin{array}{r}\cdots \\
\text { Figure } 1 \\
\text { interactio } \\
\text { weekly assig } \\
\text { presence lec } \\
\text { conten }\end{array}$ & $\begin{array}{l}\text { ucture of the course and timeline showing the } \\
\text { etween the videos, presence time (sessions) and } \\
\text { ents. Exemplary, the first two weeks and three first } \\
\text { sessions are shown. The structure, with different } \\
\text { the same for all other weeks of the semester }\end{array}$ \\
\hline
\end{tabular}

Each week a presence lecture session of 90 minutes took place. Through the flipped-classroom approach chosen the whole presence time was used for answering students' questions on the theory. The first 30 to 
45 minutes a plenary session took place for answering existing questions collaboratively. Peer- Instruction tools such as CliqR were used occasionally to obtain feedback on the level of comprehension of the theory by the students and to motivate them to question themselves their understanding of the theory. The last 60-45 minutes were used to coach each of the groups with their own specific questions (depending on their level of progress) individually.

To extend the coaching activity beyond the presence lecture time each group received a separate group blog where they could insert and post their project results and make their progress visible to the rest of the course participants. All other course members and the lecturer could read the blog. Group members were the only ones with writing and editing permits for their own group blog. Hereby I intended to provide a virtual room for coaching and giving feedback on each project progress on a more regular and individual pace. The posted results on the blogs constituted a valuable part of the unmarked formative evaluation, where I could see the level of comprehension and conceptual errors in each of the groups work as the project work developed. Answers of the peer-instruction tools and collaborative discussions during presence time were also part of the unmarked formative evaluation during the course.

As introduced above, the course design was complex and involved several tools and didactic milestones. The following subsections provide detailed insight on each of the components of the didactic design of the course as well as the theoretical background and motivation for using them.

\subsection{Project-Oriented Learning}

Project-oriented collaborative learning settings have a strong focus on the students' learning process and their particular needs, requiring teachers to act as supervisors and consultants. Being a postgraduate level course addressing such a heterogeneous students group as mentioned above represented a challenge regarding previous students' knowledge in the solar thermal field. The main aims of such a project-oriented learning setting were to (i) engage students in their learning process, (ii) facilitate it by addressing diverse students' interests as well as (iii) adapting the learning process to existing differences in their previous knowledge.

The assessment methods used for analyzing the performance of the solar systems chosen by each students group are state of the art methods used in the scientific literature for that purpose (Duffie \& Beckmann, 2013; Carrera, Camara, Casanova, Farré \& Serra., 2011; Poles \& Venturin, 2018). The application of those methods to the self-defined project allowed the students to generate new results, acquiring insight on the topic but also generating new knowledge rather than receiving existing knowledge or results from the literature. The assessment methods used allowed the students to perform a sensitivity analysis on their own results and system sizing. Thereby, students could check the plausibility and meaningfulness of their own results, contrasting them with relevant literature and with other similar projects in the course.

Students defined their own projects, based on their previous knowledge and on their own interests. Groups wanting to get deeper into the solar thermal systems design chose solar systems combined with seasonal storage, solar process or solar cooling applications. In turn, groups approaching solar thermal systems for the first time went for simple domestic hot water providing systems. This intended to actively engage students on their own self-chosen learning process and fostered an active appropriation of related knowledge.

In this sense, the didactic design of the course addresses the three main theoretical motivations for research-based learning (Karber \& Wustmann, 2015). These are: (i) participation on the scientific process; (ii) active appropriation of knowledge; (iii) development of the scientifically relevant critical-reflexive attitude.

The timeline and project milestones proposed for the students projects was the same as for the theory videos and weekly tasks. The tasks proposed for each week were the steps required to get the basic system components defined and be able to perform the project calculations successfully. The unmarked formative 
evaluation and intermediate deliverables for crosschecking each project development were the results from the proposed weekly tasks. Student group blogs, where these results and intermediate deliverables were to be uploaded facilitated as a valuable didactic tool the feedback and formative evaluation within the course. However, following that proposed timeline and content roadmap strictly was not compulsory. Students could choose their own pace for developing the project.

\subsection{Videos as Educational Resource for Enhancing Coaching}

The use of videos as part of higher education teaching has increased over the last years, "challenging the (traditional) role of the lecturer and the format of delivering course content via a lecture."(Woolfitt, 2015: page 7). There exist a wide variety of video formats which can be used in an educational context (Woolfitt, 2015). Great differences can be found on video features such use, length as well as technological challenges and effort for the lecturer. Since the main purpose of using videos in this course was to flip the classroom and use contact time as discussion and coaching time, I chose the format of "presentation slides with voice over" (Woolfitt, 2015: page 13). This format is relatively simple in its technical implementation and, thereby, suitable for a first pilot implementation of presenting the theory outside the lecture time.

The length seems to be one of the most relevant parameters influencing student's engagement (Guo, Kim \& Rubin, 2014). Guo et al. (2014) found in a vast empirical study that videos lasting between 3 and 9 minutes showed the best engagement (in terms of viewing time) from the students. For videos longer than of 9 minutes students engagement was significantly reduced. In consequence, the study concludes recommending instructors to split their videos into smaller pieces. The videos used in the course presented in this paper had a length between 17 and 32 minutes, being well over the limit recommended as optimum by the literature. I opted for the longer duration to test the viability and usability of longer videos as a compromise to reduce the processing time required from the lecturer for creating such videos as educational resources. Students had access to the full-length videos via the Vimeo (www.vimeo.com) platform, where they could watch the videos at their own pace and wished frequency.

\subsection{Weekly Learning Tasks}

To structure the project-work during the course I used weekly assignments. These assignments were noncompulsory proposed tasks relating the weekly theory input with their own project. In that sense the tasks proposed were intending to help students applying the theory to their own project, thereby aiming at fostering the transfer and link between theory and praxis. Assignments as used in the presented course are, thus, in line with learning tasks as defined by Gravett and Vella (1999) as an open question along with the resources students need to respond to the open question.

Gravett and Petersen (2002) classify learning tasks in four main types: (i) inductive tasks, which are typically used in the initial stages of the learning process and aim at encouraging students to clarify and question their knowledge and conceptions; (ii) input tasks, which aim at presenting new concepts but inviting also students to question and analyze the introduced concepts and theories but also to contest, reflect on, and challenge them; (iii) implementation tasks, aiming at a concrete development of practice skills related to the application of the presented concepts, to analyze, review, question them on a concrete context; (iv) integration tasks, which intend to consolidate the knowledge and often serve as summative assessment tasks.

The learning tasks used in the presented course design were mainly input, implementation and integration tasks. The videos were input tasks. Weekly assignments were implementation tasks aiming at the concrete transfer of the theoretical concepts to the concrete application context of each students group project. Both input and implementation tasks were proposed on a weekly basis. Table 1 shows an example of implementation tasks for given input tasks for two different weeks. 


\begin{tabular}{|c|c|c|}
\hline $\begin{array}{c}\text { Week } \\
\text { nr. }\end{array}$ & $\begin{array}{c}\text { Input tasks } \\
\text { / video } \\
\text { content }\end{array}$ & $\begin{array}{l}\text { Implementation tasks / } \\
\text { Weekly assignments }\end{array}$ \\
\hline 2 & $\begin{array}{l}\text { Solar } \\
\text { collectors }\end{array}$ & $\begin{array}{l}\text { 1. Define the collector type which would be able to meet your demands at better } \\
\text { efficiency and performance. Justifyyourchoice! } \\
\text { 2. Choose from the collector's database two different collectors of your chosen type } \\
\text { and one of a different one. With the given collector parameters, calculate the } \\
\text { efficiency of the collector for two radiation conditions }(300 \mathrm{~W} / \mathrm{m} 2 \text { and } 1000 \mathrm{~W} / \mathrm{m} 2) \\
\text { and two different temperature differences. Choose the temperature differences in } \\
\text { such a way that represent the demands your system should meet: e.g. maximum and } \\
\text { minimum or average temperature differences for the season with greatest } \\
\text { demands... } \\
\text { 3. Based on your efficiency calculations: do you need to reconsider the collector type } \\
\text { you chose? Or maybe your collector's choice? If so, repeat the previous steps until } \\
\text { you find a suitable solution for your case. }\end{array}$ \\
\hline 4 & $\begin{array}{l}\text { Thermal } \\
\text { storage }\end{array}$ & $\begin{array}{l}\text { 1. Given your particular application, infer the importance of stratification for the } \\
\text { performance of your solar system and argue on its limits and strategies promoting it } \\
\text { 2. Select a reasonable storage size for your system configuration. Try to predict in a } \\
\text { qualitative way the influence of bigger/smaller storage tanks in the system } \\
\text { performance: Why is it so? Which processes are leading to that behavior in your } \\
\text { particular system? } \\
\text { 3. Select a suitable effective heat transfer coefficient for your tank and calculate the } \\
\text { resulting insulation thickness required assuming that the effective heat transfer could } \\
\text { be calculated as the analytical heat losses coefficient. } \\
\text { 4. Based on the storage size chosen, calculate the self-discharge time for the maximum } \\
\text { supply temperature required for your system. Given the seasonal distribution of } \\
\text { your energy demands: would that be enough to overcome low radiation periods? }\end{array}$ \\
\hline
\end{tabular}

Table 1. Example of the input and implementation tasks proposed for the second and fourth week of the course

The whole project work was as such an integration task and constituted the marked summative evaluation of the course. It aimed at allowing a competence-oriented examination, making the links between all knowledge on each system component and the theoretical principles governing them analyzable and understandable, as well as to reflect on the impact and role of different principles for the whole system performance. The project work for the summative evaluation was presented in the form of a short 15 minutes presentation and 6 pages (max. 5000 words) scientific paper showing the project design, its results and conclusions.

\subsection{Blogs as Coaching Tools}

The course design presented here intended strongly to enhance the coaching dialogue between the students and the teacher. In order to extend the possibility of such coaching processes beyond the weekly lecture time, seminar blogs for each of the project-groups were settled. Seminar-blogs are a powerful tool providing space for an ongoing digitally-based collaborative communication among learners (Torio, Behrendt, Heidkamp \& Kergel, 2016). I requested students to upload their project-work and weekly assignment results onto their own seminar-blog. This was, however, requested on a voluntary basis and was not an examination requirement. The content created by the students was visible to the teacher at all times, allowing a direct feedback to take place at any time beyond the lecture times.

\section{Research Methodology}

In order to investigate the students' satisfaction with the course design and its different milestones, an anonymous self-developed survey among the course participants was conducted. Responses from 17 of the 24 participants attending the course were complete, corresponding to a participation rate of nearly 
$71 \%$ of the students in the survey. I decided to use a non-forced-choice Likert scale with an even point for all not open questions in order to give the students the possibility of showing features that could have been improved without being necessarily negative for their learning process. The survey was carried out during the last two weeks of the course via an online form on a voluntary basis. Besides the closed questions, open fields for additional comments about the course were available to allow students to formulate their main points on the strengths and weaknesses of the course design. Due to both the low number of students and the fact that a self-developed and not validated questionnaire was used, no general conclusions can be derived from the results. However, results are suitable to show plausible trends and interdependencies between the tools and didactic approaches used and the resulting students engagement and satisfaction with the course design and their learning experience.

In the following sections I present the main results and insights that can be extracted from them.

\section{Results and Discussion}

\subsection{Long Videos as Successful Educational Resource}

Figure 2 shows the average (beams) and standard deviation (error bars) of the responses to the questions related to the use of long videos as input task and educational resource for presenting the theory.

The answers show a clearly positive evaluation of the videos used. This is in line with experiences from other researchers using videos of similar length (Fowler, 2014; Valero, Martinez, Pozo \& Planas, 2018). All positively formulated items regarding the videos used reached very high values on the students' evaluation (ranging from 4.71 to 4.24 ) and very low standard deviations (ranging 0.56 to 0.75 ). Despite their extended length (about 20 to 30 minutes each video) and their simple layout (presentation slides with voice over) they were estimated to be clear and understandable and, thus, very helpful to understand the theory. Also, their role for being able to adapt the learning process to the speed of each student (fourth beam on Figure 2) shows a positive evaluation, achieving 4.52 with a standard deviation of only 0.62 points.

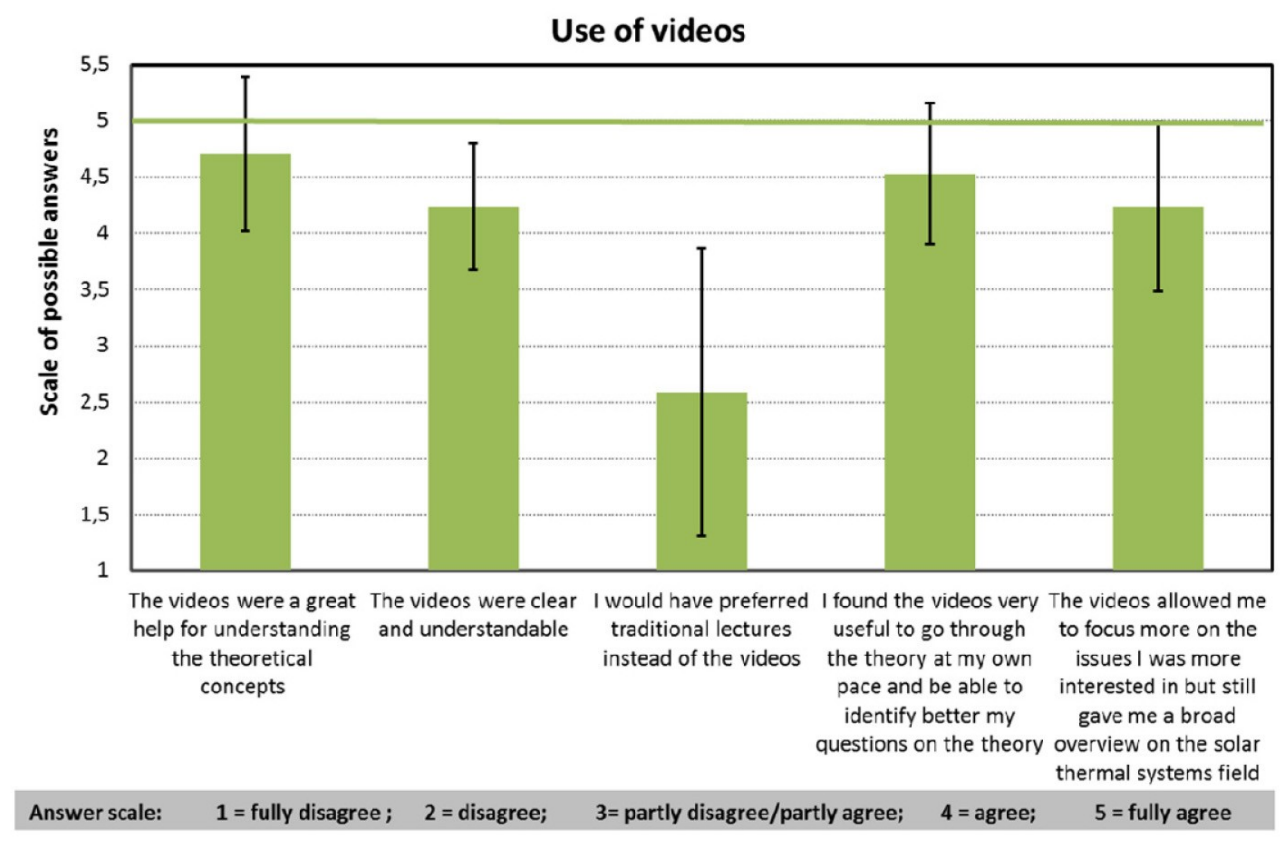

Figure 2. Average values (beams) and standard deviation (error bars) for the items related to the use of the videos as educational resource in the course

The negatively formulated item regarding the preference of traditional lectures, with 2.59 points, does not show a very clear preference of the videos over conventional teaching modes. However, the standard deviation of this item is the highest in all results obtained, with a value of 1.28: two people fully agreed 
and one person agreed preferring traditional lectures. The only comment referring explicitly to these issues was "Personally I prefer "classic" teaching as I pick up more information than through video... (since) classic classes brings me in interaction and question mode". Six people were undecided and chose the partly agree/partly disagree option. A plausible reason supporting this relatively strong undecided tendency would be the students' perception of not having enough time to deal with their particular issues during the contact weekly lecture hours (see section 3.3 for further insight into this issue). In turn, four people disagreed and another four fully disagreed with the statement, respectively. Thus, most of the students showed a positive evaluation of the videos as substitute for traditional theory lectures.

\subsection{The Role of Project Work}

Figure 3 shows the average (beams) and standard deviation in the responses about the project group work. It represented both an implementation and integration task but also consisted on the summative examination task in the end of the course.

The level of the responses is around 4 (corresponding to the answer "I agree") for all positively formulated questions. The evaluation of the project work as a tool for fostering the personal learning process (first beam in Figure 3) is predominantly positive, with an average value of 4.29 points and showing a small standard deviation (0.59).

The contribution of the project work to making the learning process to a great extent self-interest lead was positively evaluated (fifth beam, with an average value of 3.94 ) but also shows a greater standard deviation (0.90). Students could choose the particular application for their project (i.e. type of energy demands, location and resulting solar resource available). Main system components to be considered and calculation methods were however provided as guidance.

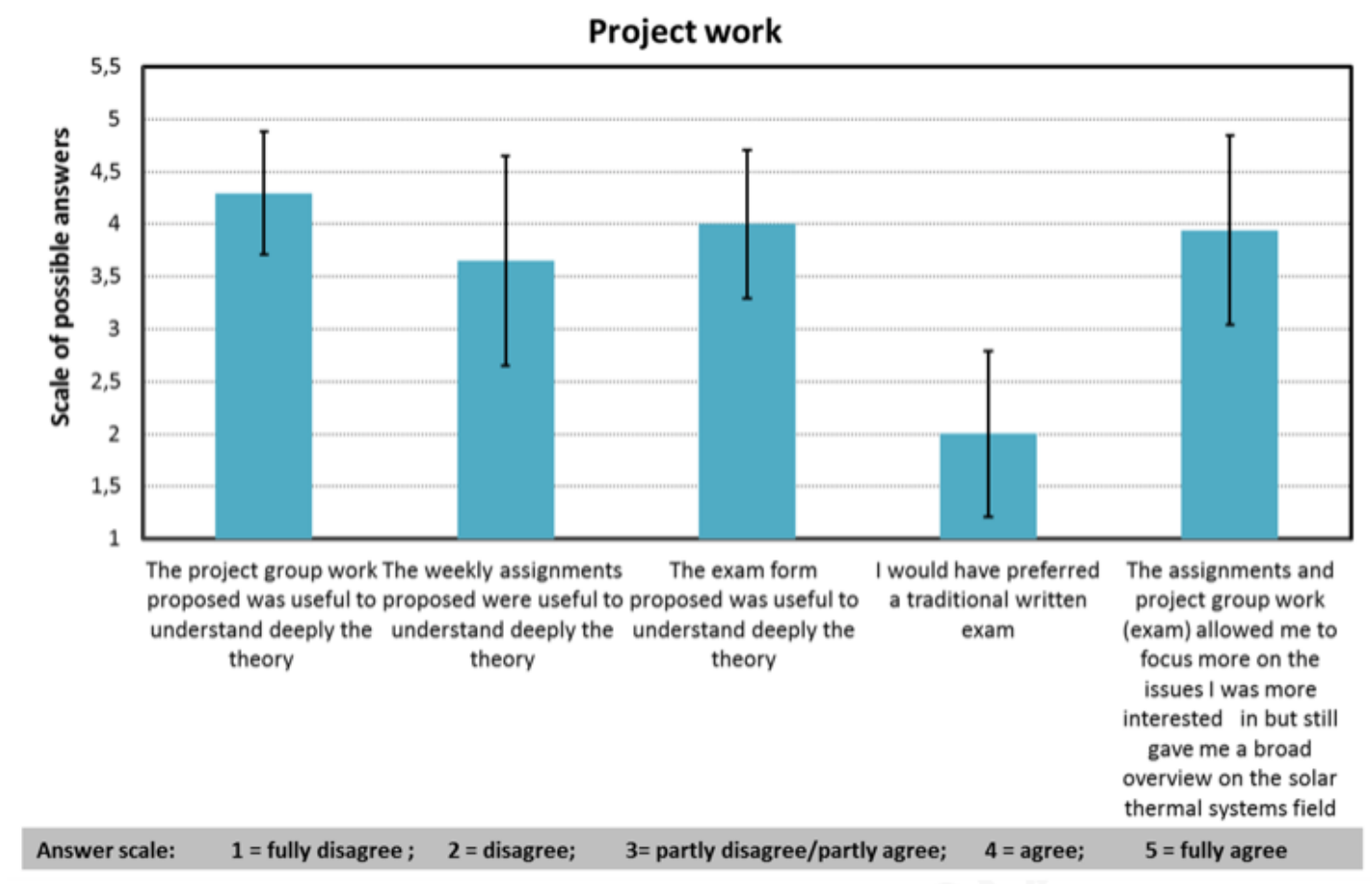

Figure 3. Average values (beams) and standard deviation (error bars) for the items related to the projectoriented work during the course

The lowest value, with 3.64 points, can be seen for the role of the weekly assignments as a help for understanding the theory. But this item also shows the greatest standard deviation of all questions related to the project work, with a value of 0.96 , indicating a bigger disagreement among the participants concerning 
this issue. The two comments from the students regarding this issue help clarifying the more negative evaluation of the role of the weekly assignments as compared to the project work in the learning process:

1. First comment: "The weekly assignments proposed were not so much useful to understand deeply the theory as it (the theory) was more orientated to the project. I would separate the weekly tasks with "basic" questions and leave the project as is." The link between the weekly assignments and the project work was not transparent to many students. This was often a matter of discussion during the coaching sessions in the presencetime. On the light of this comment the orientation of the weekly tasks (defined in this approach mainly as input, implementation and integration learning tasks according to (Gravett \& Petersen, 2002) - see section 2.3) could be redefined. Instead of being primarily oriented to develop their own project, additional inductive tasks (Gravett \& Petersen, 2002) would serve as a first intermediate link between the theory videos and its application to the project. These inductive tasks would also serve as a feedback for the lecturer on the interaction of students with the video content and direct selfcontrol to the students on their understanding of the theory.

2. Second comment: "It would have been great if there was more time for the assignments work". There was not enough time during the presence coaching sessions to effectively coach all student groups. The group blogs would have been of great help for this issue. But unfortunately, only 3 of the 12 groups used the blogs on the regularity and level of detail required to use them as coaching tool. Inductive tasks as proposed above may also foster more focused discussions and questions during the presence sessions, eventually allowing more effective coaching time for the groups.

The only negative formulated item (fourth beam in Figure 3) has a value of 2.0 and a standard deviation of 0.79 , representing a relatively strong support for the project group work chosen as examination in the course. This is in line with the positively formulated item addressing a similar question (third beam on Figure 3), whose average answer is clearly on the range of "I agree", with a small standard deviation. The main criticism of students to the project work stated in informal talks with the lecturer, was related to the additional workload it represented as compared to a written exam.

\subsection{Satisfaction with Coaching Time}

Figure 4 shows the average (beams) and standard deviation (error bars) in the responses about the students satisfaction with the coaching time during the presence sessions.

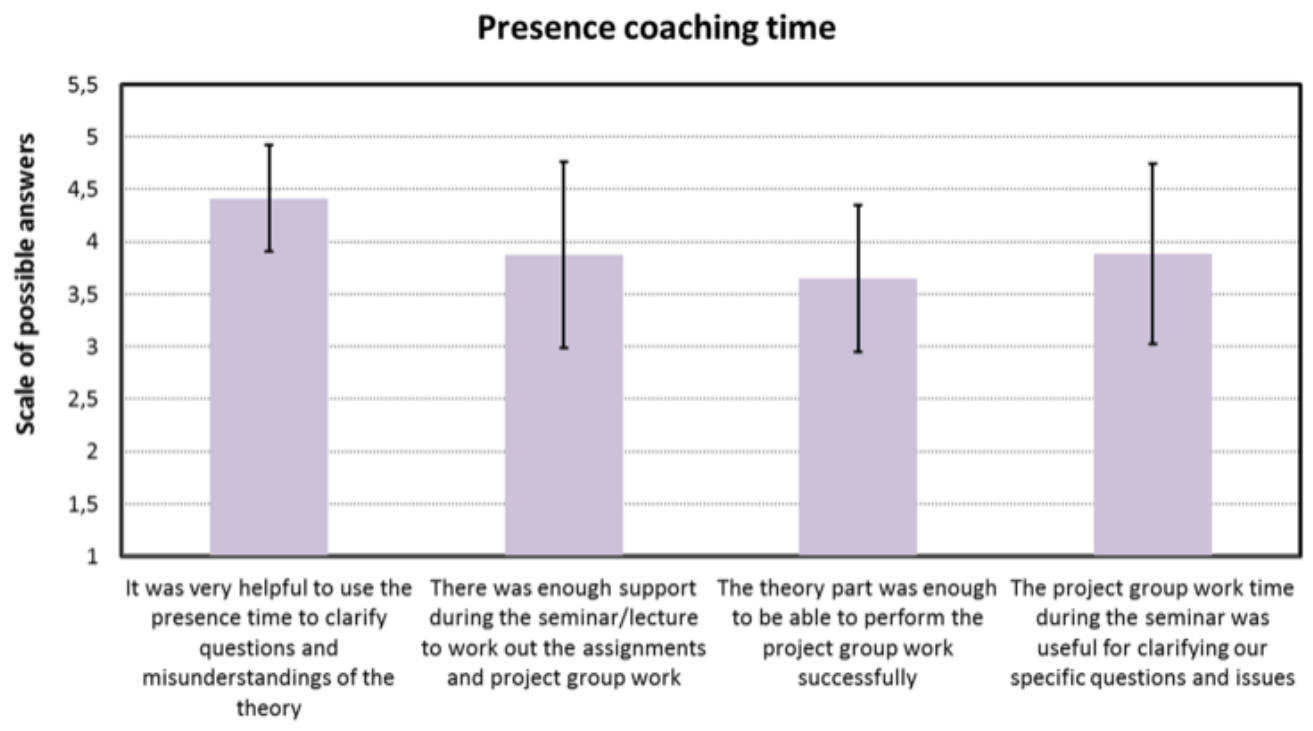

Figure 4. Average values (beams) and standard deviation (error bars) for the items related to the use of presence time as coaching time during the course 
The students evaluate the contact coaching time as positive (first beam with an average of 4.44 and a standard deviation of only 0.51 points). However, when it comes to the amount of time available, i.e. whether it was "enough" coaching time during the presence hours (second beam from the left) or the usefulness of the group work during the presence time when I was available to clarify their questions (fourth beam) the picture becomes more negative. Still, values for these items are $3.88 \pm 0.89$ and $3.81 \pm 0.83$ respectively, being yet towards a positive evaluation. A couple of comments help understanding this trend: "I felt that for the group work during lecture time there were so many groups that sometimes not all individual questions could be answered." and "The coaching time was very helpful but we were competing for time (to ask questions regarding group work) during class". Again, a more consequent use of the blogs might greatly help coping with the need for coaching and support beyond the contact hours.

\subsection{Results from Summative Evaluation as Compared to a Traditional Lecture}

The same course was taught one year before in a traditional lecture manner, before the establishment of the new teaching approach analysed in this paper. The traditional approach consisted on lectures based on power point presentations and the summative evaluation consisted on a written exam with calculation exercises and conceptual questions on the theory. The content and topics covered were very similar in both courses. However, the performance assessment method for solar thermal systems taught (F-Chart) could only be understood by the students in a theoretical manner in the traditional lecture approach since it is too complex to be part of a written exam. Instead, the F-Chart method was the core component of the project-work developed by the students in the teaching approach presented in this paper. The method is complex enough to grasp and depict the behavior of solar thermal systems for different applications. Its application to a self-chosen project by the students allowed them to gain deep insight on the influence of several system parameters and variables on the performance and suitable sizing of solar thermal systems.

Table 2 shows the main competences which were the goal in both the traditional and the new developed teaching modes. The table shows clearly that the level of competences intended with the teaching approach presented in this paper was higher than that possible in a traditional lecture mode. The different level of achievable competences is due to the more basic calculations and examples that could be performed by the students in the traditional lecture approach, resulting in a much more theoretical approximation to the field of knowledge. Instead, the project-work used in the new teaching approach lead to hands-on experience applying the theoretical concepts to a real case-study, allowing more holistic and deeper level of knowledge and competences to be acquired. The summative evaluation in this approach consisted on a scientific paper reporting the main findings from the project-work. The evaluation criteria for the paper were (i) correctness, (ii) meaningful presentation and sound understanding of the concepts involved, (iii) meaningful understanding of the interlinks between the concepts, (iv) critical reflection on the method used, (v) critical reflection on the results achieved, (vi) coherent arguing, (vii) proper use of references and citing literature, (viii) clear language and arguments, (ix) consistent structure, (x) grounded conclusions.

Figure 6 shows a histogram with the level of students achievement (in a percentage scale, from 0 to 100\%) obtained in the summative evaluation for both approaches. Despite the higher level of competences pursued in the new approach, the level of achievement of the students is clearly higher: around $54 \%$ of the students reached a performance between 95 and 100\% in the flipped-classroom project-based approach, whereas in the traditional approach only $6 \%$ of the students reached this performance. The average performance achieved with the traditional lecture was $82 \%$ (with a standard deviation of $8 \%$ ), the average level of achievement in the new approach reached $93 \%$ (with a standard deviation of 5\%). Six of the students papers achieved a scientific level similar to that found in relevant literature on the topic such as (Okafor \& Akubue, 2012). 


\begin{tabular}{|l|c|c|}
\hline $\begin{array}{l}\text { Competences: } \\
++ \text { Fully addressed; + Marginally addressed; - not } \\
\text { addressed at all }\end{array}$ & $\begin{array}{c}\text { Traditional Lecture } \\
\text { (Summative Evaluation: } \\
\text { Written Exam) }\end{array}$ & $\begin{array}{c}\text { New Teaching Approach } \\
\text { (Summative Evaluation: } \\
\text { Paper on project work }\end{array}$ \\
\hline $\begin{array}{l}\text { Good understanding of the performance of solar } \\
\text { thermal system components }\end{array}$ & ++ & ++ \\
\hline $\begin{array}{l}\text { Good understanding of the variables influencing the } \\
\text { performance of a solar thermal system }\end{array}$ & ++ & ++ \\
\hline $\begin{array}{l}\text { Understand hydraulic plans depicting different } \\
\text { configurations of solar thermal systems }\end{array}$ & ++ \\
\hline $\begin{array}{l}\text { Judge the suitability of a system layout for a given } \\
\text { application }\end{array}$ & + \\
\hline $\begin{array}{l}\text { Good understanding of the relationship between } \\
\text { components and system performance }\end{array}$ & ++ \\
\hline $\begin{array}{l}\text { Understand the differences, strengths and weaknesses } \\
\text { of the main parameters characterizing a solar thermal } \\
\text { system's behavior }\end{array}$ & + & ++ \\
\hline $\begin{array}{l}\text { Good understanding of the main parameters used for } \\
\text { characterizing the behavior of a solar thermal system }\end{array}$ & + & ++ \\
\hline $\begin{array}{l}\text { Ability to identify improvement options for } \\
\text { enhancing the performance of a given solar thermal } \\
\text { system }\end{array}$ & + & ++ \\
\hline
\end{tabular}

Table 2. Comparison of intended competences with the traditional and new developed teaching approaches

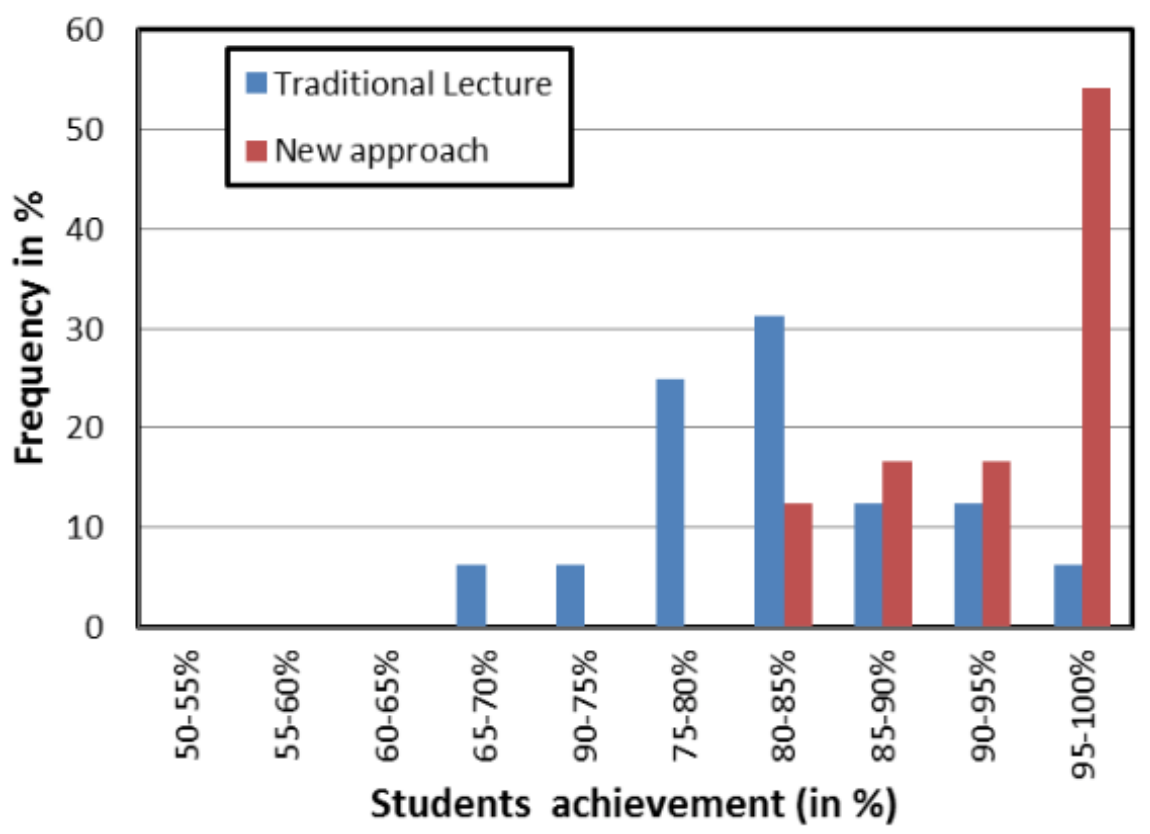

Figure 5. Histogram of students performance (in \%) in the summative evaluation in the traditional lecture and video-based flipped classroom with project-work

\subsection{Self-Perceived Achieved Competences}

The subject-specific learning goal of the course was to achieve a sound and critical understanding of solar thermal systems operation, of their sizing methods and a deep understanding of the physical principles governing these systems. Figure 6 shows the self-perceived competences of the students as compared to those rather ambitious aims (see Table 2) after participating in the course. The answers to these items show values between 4.59 and 4.00 with low standard deviations on the range of 0.6. This indicates a good success of the course in promoting a suitable and sound learning process for the students enrolled. 


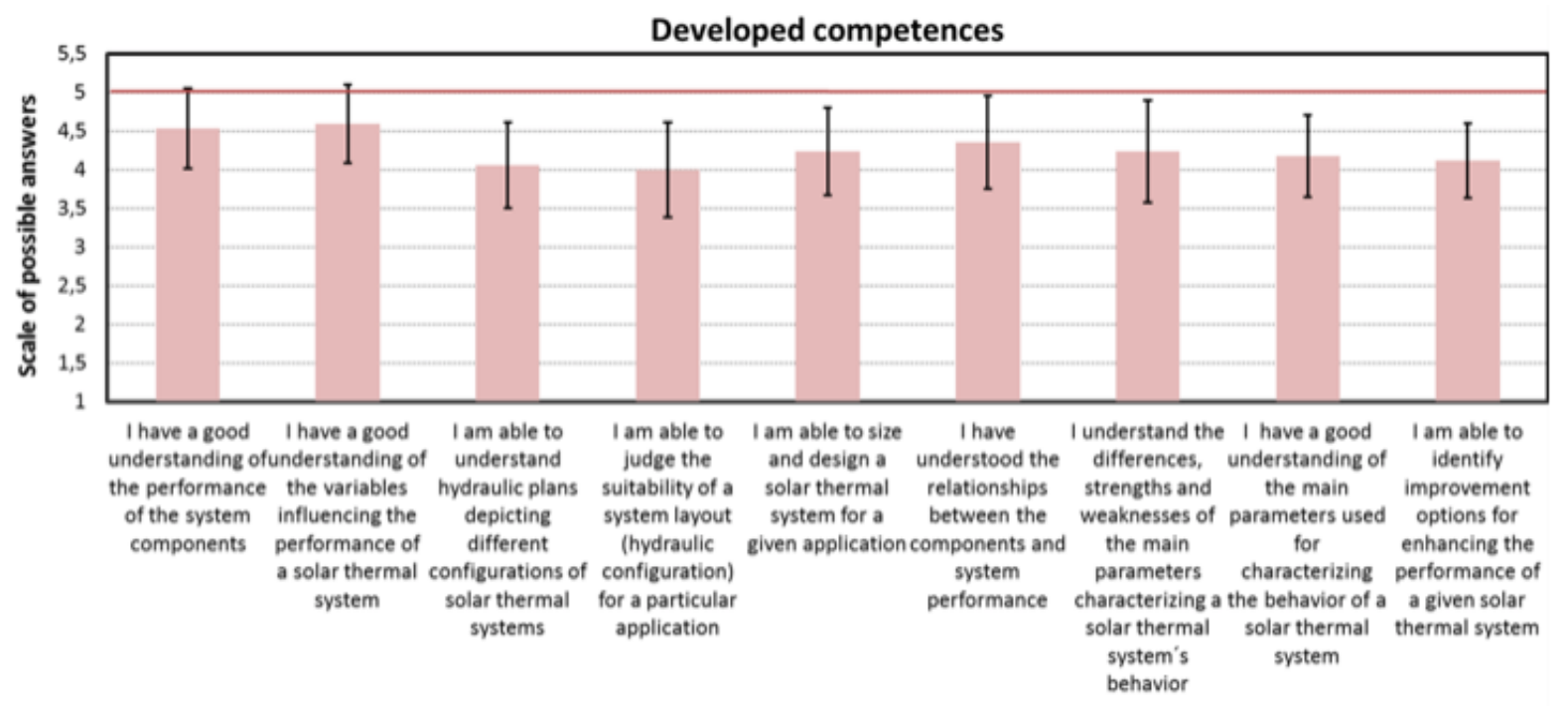

Answer scale: $\quad 1$ = was true also before the seminar; $\quad 2$ =fully disagree; $\quad 3=$ disagree; $\quad 4=$ agree; $\quad 5=$ fully agree

Figure 6. Average values (beams) and standard deviation (error bars) for the items related to the self-perceived competences developed by the students during the course

Despite the rather complex and ambitious learning goals set for the course (see Table 2, e.g. being able to size and design or to judge the suitability of a solar thermal system for a given application) the self-perceived level of fulfillment of those goals is very positive. Assessing the performance of solar thermal systems requires complex and extensive calculations able to depict the intertwining in the performance between the different system components involved. Even simplified assessment methods such as those presented in the course require a significant amount of data and calculations to be performed. Besides, sound assumptions regarding the system configuration and its layout need to be done in order to perform the calculations. The project work during the course allowed students perform all these steps with enough support to conduct them successfully. The high level of self-perceived competences by the students is in line with results from the summative evaluation shown in Figure 5. Both results indicate that a more enhanced learning experience as with the traditional lecture teaching approach was achieved.

\subsection{Discussion and Qualitative Assessment from the Lecturer}

Due to the small number of students participating in the evaluation and to the use of a self-developed questionnaire to obtain the students feedback, results presented in this paper cannot be generalized. However, they show meaningful trends about the usefulness of the implemented didactic concept and the different tools used as part of the course.

Qualitative assessment by the lecturer indicates a higher level of student motivation and engagement with the field of study than that observed by the same lecturer with a traditional teacher-centered approach in the previous year. After teaching the course with the flipped classroom approach the number of students interested in developing their master thesis project in the solar thermal field increased noticeably. Results of the students' performance in the summative evaluation are coherent with qualitative assessment from the lecturer both on the competences and cognitive understanding of the concepts presented during the course. Despite the higher level of students competences aimed at in the flipped-classroom approach students' performance was clearly higher than that achieved with the traditional teaching mode. These results are also in line with the high level of self-perceived competences achieved during the course by the students (section 4.5). In this sense, results obtained are in line with those from the literature on two of the main advantages of flipped classroom approaches in the engineering and science education context (Kerr, 2015; Valero et al. 2018), namely a greater level of students' satisfaction and better students' performance. 
One of the main aspects highlighted as positive by the students in informal feedback with the lecturer was the flexibility provided by the videos: students were able to have a look at the description of the theoretical concepts at their own pace, as many times as they required and whenever it was most suitable for them. Despite the length of the used videos (20-40 minutes) and their simple design (slides with voice-over), I could not notice any major complains about their features. Possibly the use of timestamps to facilitate students switching between the different chapters within a video helped them get along with the videos in a satisfactory manner. The additional workload related to flipped-classroom approaches is a major issue in the literature (Kerr, 2015; Valero et al. 2018). Considerations on the workload can be split on the student's workload during the course and the lecturer's additional workload for preparing the educational materials required in the flipped-classroom approach:

- Students often mentioned in informal discussions with the lecturer the higher workload as compared to other courses with the same number of credit points taught with teacher-centered lectures and having a written exam as summative evaluation. However, this point was interestingly nearly always mentioned in combination with the deeper and more long-lasting learning experience perceived by the students. Therefore, in the end it was stated to be a minor drawback and encountered wide acceptance among the students. Students from the course whose results are presented in this paper strongly encouraged other students to get enrolled in the course for coming semesters mentioning the flipped-classroom video and project-based methodology as a highlight.

- The preparation of the educational videos for the flipped-classroom methodology, as well as the setup of the course and students' blogs represented an additional workload for the lecturer. The slide presentations used for recording the voice-over videos had been prepared by the lecturer for a previous course following a traditional teacher-centered approach. Therefore, the additional workload was mainly related to the recording of the videos. For a video of about 30 minutes (as most of those used in the presented course) about 60 to 90 minutes recording time was needed, including video-post processing and multiple recordings required to correct eventual errors in the wording and formulation of the concepts in the first recording. However, once the videos are prepared their use for future courses does not represent any additional workload. In turn, setting up the students' blogs required an additional workload of about 10 minutes per blog. This workload still exists for future courses, since for every new group of students a blog needs to be settled. The sporadic use of the group blogs by the students could be identified as one of the main weak points of the proposed approach. In the course presented here blogs were not used consequently by most of the groups to upload the results. Instead, the formative evaluation which was the main intention of the students' blogs - happened during the collaborative plenary discussions or the coached group work during the presence sessions. As a result, presence time was not enough to coach all the groups and additional time was offered by the lecturer for coaching all the groups. This resulted in a relevant additional workload (qualitative estimations lead to $1 \mathrm{~h}$ per week required for this aim). This additional workload could significantly be reduced if blogs are consequently used by the students groups. To tackle this issue in the future, blogs can be used for reporting project-work results as the summative evaluation of the course.

\section{Conclusions}

The combined use of long and easy to produce (slides with voice-over) theory videos, fostering a flipped-classroom teaching mode, with a project-based arrangement presented here have shown to be promising tools for successfully promoting active and significant learning.

Despite strongly deviating from the benchmarks for educational videos found in the literature, the videos used in this course were positively evaluated. Although additional research is required to validate the suitability of long videos as educational resource in graduate higher education and the resulting student satisfaction with those, long and easy to produce theory videos used in this study showed a high level of students satisfaction and proved to be a suitable tool for making the theory understandable. After the first 
pilot implementation of such videos as educational resource for explaining complex fundamental concepts and performance assessment methods of solar thermal systems I found a higher level of students' motivation and engagement with the field of study as well as higher students' performance and achievement.

Thus, I argue firstly (i) that even simple and relatively easy to produce videos are a suitable educational tool for presenting complex theoretical concepts and secondly (ii) that videos are a suitable and very useful tool for promoting successful flipped-classroom approaches, enabling to transform into coaching time the presence lecture time. This result could strongly encourage lecturers and faculty members to use tailored and self-made videos for explaining theoretical concepts within their lectures. The contribution of the project work to make the learning process to a great extent self-interest lead was positively evaluated. The project-work chosen also proved to represent a sound link to the videos, being a great help for understanding the theory in them. For facilitating the link between the theory and its application into the project work and make students their appraisal of the theory more obvious, inductive tasks should be as a suitable tool. Although leading to a higher workload for the students than that in other courses following a traditional teaching approach, students were generally satisfied with the project work. It possibly represented a strong and meaningful facilitator for the high students' achievement and enabled the high level of self-perceived competences reported by the students, despite the rather complex and ambitious learning goals. Both indicators represent a good proof of a significant learning experience within the course.

Students reported agreeing with the helpfulness of using lecture time as coaching time. However, additional coaching time was required beyond the presence time, representing a significant additional workload for the lecturer. A more consequent use of the blogs proposed as part of the formative evaluation could possibly reduce this mismatch. Thus, for future courses with this methodology, blogs could be proposed as summative evaluation for presenting project work results, representing an incentive for a more continuous use of them in all the groups.

Results in this paper show encouraging trends for using video-based flipped-classroom approaches combined with students project work. The simplicity of the produced videos could encourage other lecturers using this approach for their courses. However, implementing even this easy to produce videos for the first time implies an additional workload for faculty. Additional coaching time beyond the presence lecture sessions required by students also represents an additional workload which, on the contrary to video production, would not be reduced for the same course taught in future semesters. Benefits from this additional workload seem promising and may encourage faculty to implement such didactic approaches. Yet, more detailed studies for quantifying the additional workload for the lecturer and students and exploring the usability of availavailable didactic tools (such as blogs or others) to reduce this workload are required.

\section{Declaration of Conflicting Interests}

The author declares no potential conflicts of interest with respect to the research, authorship, and/or publication of this article.

\section{Funding}

The author received no financial support for the research of the results presented in this paper. For publication of this article the author thanks the DfG Open Access Publication Funds obtained from the University of Oldenburg.

\section{References}

Arnold R. (2013). Systemische Erwachsenenbildung - Die transformierende Kraft des begleiteten Selbstlernens.

Baltmannsweiler: Schneider Hohengehren. 
Berkemeyer, N., \& Schneider, R. (2009). Lehrerbildung in der Wissenschaft. In Wandel der Lebr-und Lernkulturen, hrsg. (121-147). Bielefeld: Bertelsmann.

Blom, H. (2000). Der Dozent als Coach. Neuwied/Kriftel: Luchterhand.

Bonvillian, W.B., \& Singer, S.R. (2013). The Online Challenge to Higher Education. Issues in Science and Technology, 29(4). Online Access: http://issues.org/29-4/the-online-challenge-to-higher-education/

Carrera, A., Camara, O., Casanova, M., Farré, M., \& Serra, I. (2011). New calculation methodology for solar thermal systems. Prepublicació no. 19, setembre. Departament de Matemàtiques. Available at: http://www.uab.cat/matematiques https://doi.org/10.18086/swc.2011.28.05

Dadach, Z.E. (2013). Quantifying the Effects of an Active Learning Strategy on the Motivation of Students. International Journal of Engineering Education, 29(4), 1-10.

Duffie, J.A., \& Beckmann, W.A. (2013). Solar Engineering of Thermal Processes (4th ed.). John Wiley \& Sons, Inc. https://doi.org/10.1002/9781118671603

Fowler, M.L. (2014). Flipping Signals and Systems - Course Structure \& Results. In IEEE International Conference on Acoustics, Speech and Signal Processing (ICASSP) (2219-2223). Florence, Italy.https://doi.org/10.1109/ICASSP.2014.6853993

Fry, H., Ketteridge, S., \& Marshall, S. (Eds.), (2009). A Handbook for Teaching and Learning in Higher Education: enbancing academic practice (3rd ed.). New York: Routledge, Taylor and Francis Group.

Guo, P.J, Kim, J., \& Rubin R. (2014). How video production affects student engagement: An empirical study of MOOC videos. Proceedings of the first ACM conference on Learning@ Scale Conference, March.https://doi.org/10.1145/2556325.2566239

Gravett, S., \& Petersen, N. (2002). Structuring Dialogue with Students via Learning Tasks. Innovative Higher Education, 26, 281. https://doi.org/10.1023/A:1015833114292

Gravett, S., \& Vella, J. (1999). Learning facilitation for adults. Study guide. Johannesburg: RAU Centre for Distance Education.

Karber, A. \& Wustmann, C. (2015). Forschendes Lehren und Lernen - Perspektiven der Akteurinnen und Akteure in den Blick nehmen und erforschen. In Egger, R. et al. (Hrsg.), Forschungsgeleitete Lehre in einem Massenstudium, Lernwelfforschung ,13, Springer Fachmedien Wiesbaden. https://doi.org/10.1007/978-3-65803231-9_2

Kerr, B. (2015). The flipped classroom in engineering education: a survey of the research. International Conference on Interactive Collaborative Learning (ICL) IEEE, (815-818). Florence, Italy. https://doi.org/10.1109/ICL.2015.7318133

Missenyanni, A., Lytras, M.D., Papadopoulou, P., \& Marouli, C. (2018). Active Learning Strategies in Higher Education: Teaching for Leadership, Innovation, and Creativity. Innovative Higher Education, 25(2). https://doi.org/10.1108/9781787144873

McDaniel, E.A., Dell Felder, B., Gordon, L., Hrutka, M.E., \& Quinn, S. (2000). New Faculty Roles in Learning Outcomes Education: The Experiences of Four Models and Institutions. Innovative Higher Education (2002), 26, 281.

Okafor, I.F., \& Akubue, G. (2012). F-chart Method for Designing Solar Thermal Water Heating Systems. International Journal of Scientific and Engineering Research, 3(9), September, 69-75.

Poles, S., \& Venturin, M. (2018). Design and modeling the utilizability F-chart method for active solar energy systems. Open Source Engineering. Available at: http://www.openeering.com/sites/default/files/Active_Solar_Energy_Systems.pdf 
Schneider, R., Szcyrba, B., Welbers, U., \& Wildt, J. (2009). Einleitung. In: Wandel der Lehr- und Lernkulturen (5-13). Bielefeld: Bertelsmann

Torio, H., Behrendt, T., Heidkamp, B., \& Kergel, D. (2016). Fostering Participation and Transparency in Laboratory Higher Education - Experiences with the "Seminar Blog". In Proceedings of the International Conference New Perspectives in Science Education - 5th Edition (337-342). Florence 16-18 March.

Torío, H., \& Brudler, E., (2015). Competence in Teaching in the Renewable Energy Field -an Encouragement for Exchange. In: Proceedings of the International Conference New Perspectives in Science Education - 5th Edition (686-692). Florence 16-18 March..

Valero, M.M., Martinez, M., Pozo, F., \& Planas, E. (2018). A Successful Experience with the Flipped Classroom in the Transport Phenomena Course. Education for Chemical Engineers. 26, 67-79. https://doi.org/10.1016/j.ece.2018.08.003

Waltdrop, M. (2015). Why we are teaching science wrong, and how to make it right. Nature, International weekly journal of science, 523, 272-274. https://doi.org/10.1038/523272a

Wildt, J., (2005). Vom Lebren zum Lernen hochschuldidaktische Konsequenzen aus dem Bologna-Prozess für Lehre, Studium und Prüfung. Kurzfassung eines Vortrags zur: Expertentagung des EWFT, From Teaching to Learning, Berlin. Available at: http://www.ewft.de/files/Wildt-05-Vom\%20Lehren\%20zum\%20Lernenhochschuldidaktische $\% 20$ Konsequenzen.pdf

Wildt, J. (2011). "Forschendes Lernen" als Hochform aktiven und kooperativen Lernens. In Diedrich, R. (Hrsg.), Ökonomisierung der Wissensgesellschaft. Wie viel Ökonomie braucht und wie viel Ökonomie verträgt die Wissensgesellschaft (93-108). Berlin: Duncker\&Humblot.

Woolfitt, Z. (2015). The effective use of videos in higher education.Lectoraat. Teaching, Learning and Technology Inbolland University of Applied Sciences. October. Available at: https://www.inholland.nl/media/10230/the-effective-use-of-video-in-higher-education-woolfitt-october-2015.pdf

Published by OmniaScience (www.omniascience.com) Journal of Technology and Science Education, 2019 (www.jotse.org)

Article's contents are provided on an Attribution-Non Commercial 4.0 Creative commons International License. Readers are allowed to copy, distribute and communicate article's contents, provided the author's and JOTSE journal's names are included. It must not be used for commercial purposes. To see the complete licence contents, please visit https://creativecommons.org/licenses/by-nc/4.0/. 